\title{
Subclinical Listonella anguillarum infection does not impair recovery of swimming performance in rainbow trout Oncorhynchus mykiss
}

\author{
Keith B. Tierney ${ }^{1, *}$, Shannon K. Balfry ${ }^{2}$, Anthony P. Farrell ${ }^{2}$ \\ ${ }^{1}$ Department of Biological Sciences, Simon Fraser University, Burnaby, British Columbia V5A 1S6, Canada \\ ${ }^{2}$ Faculty of Land and Food Systems, University of British Columbia, Vancouver, British Columbia V6T 1Z4, Canada
}

\begin{abstract}
This study examines whether injections of the commonly used bacterial-challenge pathogen Listonella anguillarum (formerly Vibrio anguillarum) negatively impact the ability of rainbow trout Oncorhynchus mykiss Walbaum to perform repeat swimming trials. Fish were given intraperitoneal injections of either a sub-lethal $\left(10^{5}\right.$ colony forming units; CFUs) or a lethal $\left(10^{7} \mathrm{CFUs}\right)$ dose of $L$. anguillarum, held for $48 \mathrm{~h}$, and then given 2 successive ramp critical swimming speed ( $\left.U_{\text {crit }}\right)$ tests separated by $45 \mathrm{~min}$. Compared with saline-injected control fish, the low-dose injection did not significantly impair swimming performance and recovery. Similarly, $U_{\text {crit }}$ and re-performance for fish surviving the high-dose injection were comparable to control ( 2 of 6 fish died after injection and before testing). In contrast, a positive control test of seawater challenge did impair recovery of swimming performance. In view of these results and common use of L. anguillarum as a challenge pathogen for toxicological studies, it seems unlikely that the consequences of pathogenesis impact the important cardiorespiratory changes associated with exercise.
\end{abstract}

KEY WORDS: Listonella anguillarum · Vibriosis · Seawater · Swimming performance $\cdot$ Recovery · Critical swimming speed $\cdot U_{\text {crit }}$

\section{INTRODUCTION}

Listonella anguillarum (basionym Vibrio anguillarum) is a naturally occurring bacterial pathogen and the etiological agent of vibriosis, known to cause substantial mortality in farmed and wild salmonid stocks. Vibriosis is primarily a disease of salt and brackish waters (Egidius 1987) that often occurs when cultured salmonids are relocated to saltwater (Egidius \& Andersen 1979). The purpose of the present study was to test the hypothesis that subclinical $L$. anguillarum infection impairs swimming performance of rainbow trout Oncorhynchus mykiss.

Behaviors such as feeding, predator avoidance and migration all rely on swimming ability (Beamish 1978), so it is axiomatic that any impairment to swimming could impact other aspects of physiology and behavior. Interactions between swimming performance and immunological stress have been reported previously. For example, the swimming endurance of bull trout Salvelinus confluentus was $\sim 20 \%$ decreased by Renibacterium salmoninarum infection (Jones \& Moffitt 2004 ), and critical swimming speed ( $\left.U_{\text {crit }}\right)$ was $\sim 13 \%$ lower in Atlantic salmon Salmo salar with high numbers of sea lice Lepeophtheirus salmonis (Wagner et al. 2003) and $~ 18 \%$ lower in Delta smelt Hypomesus transpacificus with Mycobacterium sp. infections (Swanson et al. 2002). The ability of fish to recover from a $U_{\text {crit }}$ test can also be impaired with disease. Indeed, wild, adult sockeye salmon Oncorhynchus nerka with incidental Listonella (Vibrio) and Sporocytophagosis infections were unable to recover within $1 \mathrm{~h}$ from a $U_{\text {crit }}$ test and could only reach $\sim 61 \%$ of an earlier $U_{\text {crit }}$ on a second $U_{\text {crit }}$ test (Jain et al. 1998). Whether the Listonella infection was the causative factor in decreasing swimming performance has not 
been tested. Therefore, the principle aim of this study was to examine the effect of $L$. anguillarum injections on rainbow trout swimming and recovery ability using repeated ramp- $U_{\text {crit }}$ testing (Jain et al. 1997).

\section{MATERIALS AND METHODS}

Fish. Rainbow trout (mass $379 \pm 12 \mathrm{~g}$, fork length $29.8 \pm 0.3 \mathrm{~cm}$ ) were acquired from Sun Valley Trout Farm (Mission, BC) and maintained in flow-through dechlorinated municipal water (temperature $8.9 \pm$ $0.3^{\circ} \mathrm{C}_{i}$ dissolved oxygen $>8 \mathrm{mg} \mathrm{O}_{2} \mathrm{l}^{-1}$ ) at the Department of Fisheries and Oceans/University of British Columbia (DO/UBC) Centre for Aquaculture and Environmental Research (West Vancouver, BC). Fish were fed commercial trout chow ad libitum once daily.

Swimming performance protocol. Swimming measurements were performed in a 215 l, mobile Bretttype respirometer described in Farrell et al. (2003). Individual trout were taken to stage 3 anesthesia (Summerfelt \& Smith 1990) with $0.2 \mathrm{mg} \mathrm{l}^{-1} \mathrm{MS} 222$ (Tricaine methanesulfonate, Syndel Laboratories) in buffered freshwater $\left(\mathrm{NaHCO}_{3} 0.2 \mathrm{mg} \mathrm{l}^{-1}\right)$ for mass and length measurements and to facilitate placement into the swim chamber. Fish recovered for $45 \mathrm{~min}$ at a low water speed (0.3 body lengths [BL] s ${ }^{-1}$ ), which allowed fish to remain stationary on the bottom of the chamber without swimming. After the recovery period, trout were given a conditioning swim that consisted of an abbreviated step velocity test (described in Jain et al. 1997). For the conditioning swim, water speed was increased in regular increments of $0.15 \mathrm{BL} \mathrm{s}^{-1}$ every 2 min until the fish was unwilling to swim faster and rested on the electric grid at the rear of the swim chamber. The conditioning swim was intended to eliminate the potential training effect of repeat swimming (Farlinger \& Beamish 1978, Jain et al. 1997) and also provide an index of individual performance to set the ramp velocities. Following acclimation and beginning at approximately the same time of day (11:00 to $12: 00 \mathrm{~h})$, fish were given a ramp- $U_{\text {crit }}$ test as described by Jain et al. $(1997,1998)$. For ramp- $U_{\text {crit }}$ testing, each fish was brought up to $\sim 75 \%$ of the maximum speed achieved in the conditioning swim using $5 \mathrm{~min}$ increments of $0.15 \mathrm{BL} \mathrm{s}^{-1}$. Following this, 20 min increments of $0.15 \mathrm{BL} \mathrm{s}^{-1}$ were given until the fish reached failure. Failure was judged to have occurred when the fish impinged on the rear electrified grid for a period of at least $20 \mathrm{~s}$. $U_{\text {crit }}$ was calculated as in Brett (1964), where $U_{\text {crit }}=U_{\mathrm{fi}}+\left(t_{\mathrm{f}} / t_{\mathrm{i}}\right) U_{\mathrm{i}}$, and $U_{\mathrm{fi}}$ is the water velocity of the last fully completed increment, $t_{\mathrm{f}}$ is the time spent on the last step, $t_{\mathrm{i}}$ is $20 \mathrm{~min}$, and $U_{\mathrm{i}}$ is the increment of $0.15 \mathrm{BL} \mathrm{s}^{-1}$. After a $45 \mathrm{~min}$ recovery period at acclimation water speed $\left(0.3 \mathrm{BL} \mathrm{s}^{-1}\right)$, a second identical ramp-
$U_{\text {crit }}$ test was given to determine $U_{\text {crit2 }}$. The repeat $U_{\text {crit }}$ protocol was chosen since healthy salmonids are capable of repeating exhaustive swimming after as little as a 40 min recovery (Farrell et al. 1998, 2003, Jain et al. 1998, Lee et al. 2003), whereas stressed or ill salmonids are not (Farrell et al. 1998, Jain et al. 1998, Tierney et al. 2004).

Validation of experimental approach. Traditional $U_{\text {crit }}$ testing includes a lengthy overnight acclimation period (e.g. Brett 1964, Nikl \& Farrell 1993), which in a flow-through situation may produce much wastewater and potential for Listonella anguillarum release. However, Peake et al. (1997) demonstrated that hatchery trout reached the same $U_{\text {crit }}$ regardless of acclimation length. Therefore we shortened the acclimation period as a means of reducing wastewater production and the risk of pathogen release. To confirm these earlier results, we first verified that reducing the overnight (12 to $14 \mathrm{~h}$ ) acclimation to only $2 \mathrm{~h}$ had no significant effect on $U_{\text {crit }}$ and its re-performance. Fish tested after a conventional overnight acclimation period had a $U_{\text {crit1 }}$ (first $U_{\text {crit }}$ test) of $1.62 \pm 0.06 \mathrm{BL} \mathrm{s}^{-1}(\mathrm{n}=6)$, and repeated that performance after a $40 \mathrm{~min}$ recovery period, reaching an identical speed $\left(U_{\text {crit2 }}=1.64 \pm\right.$ $0.07 \mathrm{BL} \mathrm{s}^{-1}$ ). With a $2 \mathrm{~h}$ acclimation, $U_{\text {crit }}$ and re-performance were identical $(\mathrm{p}=0.540 ; \beta=0.811)\left(U_{\text {crit1 }}=\right.$ $1.67 \pm 0.02 \mathrm{BL} \mathrm{s}^{-1}$, and $\left.U_{\text {crit2 }}=1.67 \pm 0.05 \mathrm{BL} \mathrm{s}^{-1} ; \mathrm{n}=6\right)$ ), confirming the work of Peake et al. (1997). Consequently, we were confident that our main experiments could be conducted using a short acclimation protocol.

We further validated our repeated $U_{\text {crit }}$ protocol with a positive control by testing swimming performance after a $48 \mathrm{~h}$ seawater challenge (SWC). Brauner et al. (1994) earlier demonstrated that a $24 \mathrm{~h}$ SWC impaired recovery from a $U_{\text {crit }}$ test, with both wild and hatchery rainbow trout reaching $<85 \%$ of $U_{\text {crit1 }}$ on a second swim about $4 \mathrm{~h}$ later. We replaced the freshwater supply with seawater supplied at a similar temperature $\left(\sim 10^{\circ} \mathrm{C}\right)$ for $48 \mathrm{~h}$, and following a $24 \mathrm{~h}$ recovery period, 1 fish was tested daily on 4 consecutive days $(n=4)$. $U_{\text {crit1 }}\left(1.41 \pm 0.1 \mathrm{BL} \mathrm{s}^{-1}\right)$ was significantly reduced from control fish above $(p=0.012 ; \beta=1.00)$, and was independent of the time post exposure ( 2 to $6 \mathrm{~d}$ ). Most of the seawater challenge fish did not recover from $U_{\text {crit1 }}$ : 3 of 4 fish died during the $45 \mathrm{~min}$ recovery period. The only surviving fish (tested on Day 5 ) reached $\sim 25 \%$ of the initial swim speed (0.44 vs. $\left.1.57 \mathrm{BL} \mathrm{s}^{-1}\right)$. Clearly, repeat swimming performance testing can resolve physiological impairment against a control and demonstrates that $U_{\text {crit }}$ re-performance is a meaningful measure. Although Brauner et al. (1994) did not find mortality following seawater exposure, mortality following exhaustive swimming is not uncommon; it has been recorded for a variety of species (Black 1958), including similarly sized rainbow trout (Wood et al. 
1983). However, mortality has not been observed in any previous repeat swimming work (e.g. Jain et al. 1997, Farrell et al. 1998, 2003, Lee et al. 2003).

Power analysis. For the main treatment (injected) groups of the disease experiments, power analysis was used to determine sample size. Since acclimation length had no impact on $U_{\text {crit }}$ or its recovery, short and long acclimated fish were pooled $(\mathrm{n}=12)$, and based on the resulting $U_{\text {crit1 }}$ and its standard deviation (mean = $1.65, \mathrm{SD}=0.10$ ) and the magnitude of changes observed in other studies of disease and swimming (e.g. $13 \%$ Jain et al. 1998, and 18\% Swanson et al. 2002), significant differences in treatment fish would be detectable at $n=5$ while power would remain $>0.80$.

Disease experiments. Primary isolates of Listonella anguillarum (Pacific Biological Station, Nanaimo, BC isolate no. R20, serotype 01) were obtained from coho salmon Oncorhynchus kisutch that had died from being previously inoculated with the pathogen. $L$. anguillarum cells were cultured on tryptic soy agar (TSA supplemented with $1.5 \% \mathrm{NaCl}$ ) plates for $18 \mathrm{~h}$, harvested, and transferred to sterile chilled saline $(0.85 \% \mathrm{NaCl})$. The concentration of $L$. anguillarum was estimated from absorbance measurements made at $540 \mathrm{~nm}$ (540 optical density [OD] estimated to contain $\sim 110$ cells $\mathrm{ml}^{-1}$ ). The actual concentration of colony forming units (CFUs) was subsequently determined for each inoculum by drop plating $(25 \mu \mathrm{l})$ serial dilutions onto TSA plates. The plates were then incubated overnight and the number of colonies was counted to calculate the number of cells $\mathrm{ml}^{-1}$ of inoculum. Fish were intraperitoneally injected with a $0.1 \mathrm{ml}$ L. anguillarum saline mixture. Five fish were given the low dose $\left(1.67 \times 10^{5} \pm 1.53 \times 10^{4} \mathrm{CFUs}\right)$, and 6 fish were given the 100 -fold higher dose $\left(2.36 \times 10^{7} \pm 4.00 \times\right.$ $\left.10^{6} \mathrm{CFUs}\right)$. The low dose was chosen because it had proven efficacious at inducing vibriosis in rainbow trout in earlier work (Ackerman et al. 1999, Ackerman \& Iwama 2001). To control for any effects of the injection or treatment system, 5 additional fish were injected with $0.1 \mathrm{ml}$ sterile saline alone $(0.85 \% \mathrm{NaCl})$. After injection, individual fish were placed into $200 \mathrm{l}$ aerated tanks kept at acclimation temperature $\left(\sim 10^{\circ} \mathrm{C}\right)$. Water was changed once after $24 \mathrm{~h}$. All fish were held for $48 \mathrm{~h}$ prior to measuring swimming performance, as a similar amount of pathogen had previously been shown to cause physiologic changes within this timeframe (Ackerman \& Iwama 2001).

Post-swim evaluation. Following swimming experiments, fish were sacrificed using cervical dislocation. For injected fish, liver, spleen, and kidney tissue samples were taken aseptically, and streaked onto TSA plates. Fish were assumed to have vibriosis if Gramnegative, motile, curved rod-shaped bacteria were isolated from non-pigment producing, circular, cream- colored colonies, isolated on the TSA plates (DFO 1984). Leucocrit (Lct) and hematocrit (Hct) measurements were taken for saline and low-dose-injected fish. Blood was collected into $40 \mu \mathrm{l}$ heparinized capillary tubes (VWR Canlab) and centrifuged at $10000 \times g$ for 2.5 min using an IEC Microcentrifuge (International Equipment Company). Hct and Lct measurements were made with the assistance of precision calipers under magnification (as described by McLeay \& Gordon 1977).

Statistics. To determine if there were any treatment effects on repeat swimming ability, $U_{\text {crit2 }}$ was regressed on $U_{\text {crit1 }}$ (in $\mathrm{cm} \mathrm{s}^{-1}$ ) using length as a covariate. As there were no treatment effects on $U_{\text {crit }}$ repeatability, average swim speed was determined and regressed against treatment. Comparisons were then made on the residuals. Length was not a significant covariate, and so to facilitate comparisons to other studies (e.g. Jain et al. 1997, Claireaux et al. 2005), swim speed was subsequently reported standardized to length $\left(\mathrm{BL} \mathrm{s} \mathrm{s}^{-1}\right)$. Hct and Lct data were arcsine transformed and compared using ANOVA. Statistics and graphing were carried out using JMP 5.0 (SAS), SigmaStat 3.0 and SigmaPlot 8.0 (SPSS Scientific). Unless stated otherwise, reported values are mean \pm standard error of the mean (SEM).

\section{RESULTS}

\section{Swimming performance}

Saline-injected and uninjected hatchery rainbow trout performed the same ( $U_{\text {crit1 }} 48.4 \pm 0.92$ and $49.6 \pm 1.27 \mathrm{~cm}$ $\mathrm{s}^{-1}$ or $1.65 \pm 0.031 .62 \pm 0.04 \mathrm{BL} \mathrm{s}^{-1}$, respectively). Furthermore, both groups recovered this initial performance, so $U_{\text {crit1 }}$ was a good predictor of $U_{\text {crit2 }}$ (Fig. 1a). Accordingly, the injection protocol used herein had no effect on swimming or recovery performance.

Vibriosis was confirmed during a post-mortem examination for all the low- and high-dose-injected fish but none of the saline-injected fish. No external or internal clinical signs of disease were evident in any fish. Hct was high and did not differ between salineinjected fish (42 $\pm 2 \%$ ) and low-dose Listonella anguillarum-injected fish $(45 \pm 2 \%)$. Lct also did not differ between saline-injected and $L$. anguillarum-injected fish $(p=0.058)$, but statistical power was low $(\beta=0.40)$ because Lct was undetectable in all 5 of the low-dose fish (Lct $=0 \%$, and 2 of the 5 saline-injected fish $($ Lct $=0.86,0.00,1.09,0.49,0.00)$.

Low-dose injection did not negatively impact swimming performance or its recovery. (Fig. 1a). However, fish that received a low-dose injection $\left(10^{5} \mathrm{CFUs}\right) 48 \mathrm{~h}$ earlier had higher $U_{\text {crit }}$ values, as evidenced by signifi- 


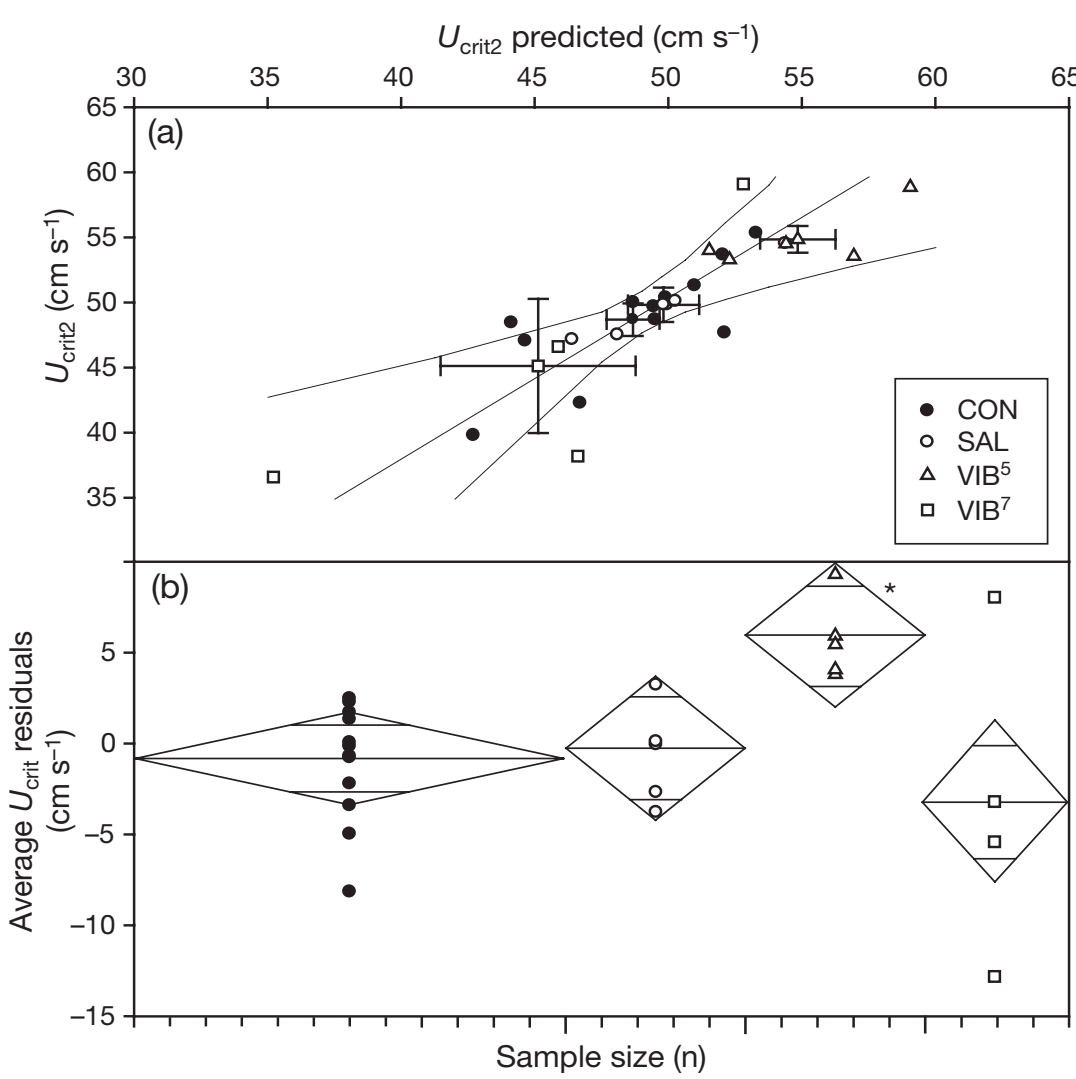

Fig. 1. Oncorhynchus mykiss. (a) The second critical swimming speed ( $\left.U_{\text {crit2 }}\right)$ versus the predicted $U_{\text {crit2 }}$ (based on $U_{\text {crit1 }}$, determined earlier) for control $(\mathrm{CON})$ and saline (SAL), low- $\left(10^{5}\right)$ or high- $\left(10^{7}\right)$ dose Listonella anguillarum- (VIB ${ }^{5}$ and $\mathrm{VIB}^{7}$, respectively) injected adult hatchery rainbow trout (ANCOVA, length as a covariate). Lines are for CON and SAL regression $\pm 95 \% \mathrm{CIs} ;$ mean \pm SEM are plotted for each group. As there were no differences in successive swimming abilities, (b) residuals of an average swim speed versus treatment regression were determined and plotted. Diamond

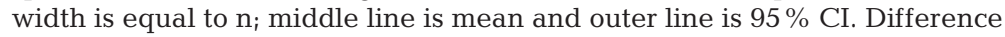
from control is denoted by an asterisk

cantly greater positive residuals (Fig. 1b). Differences remain apparent when the data are considered standardized for length, with low-dose-injected fish reaching a $16.6 \%$ higher $U_{\text {crit }}$ (in $\mathrm{BL} \mathrm{s}^{-1} ; \mathrm{p}<0.05, \beta=1.00$ ) than the saline-injected fish $\left(U_{\text {crit1 }}=1.90 \pm 0.03 \mathrm{BL} \mathrm{s}^{-1}\right.$, and $U_{\text {crit2 }}=1.88 \pm 0.03 \mathrm{BL} \mathrm{s}^{-1}$ ) (Fig. 2). The higher $U_{\text {crit }}$ value for the low-dose fish appeared due to an increase in their willingness to use burst-and-coast swimming during the later stages of the trials. In saline-injected fish, swimming cessation coincided with a transition from a steady to an unsteady swimming gait.

Only 4 of 6 fish survived injection with the higher dose of Listonella anguillarum $\left(10^{7} \mathrm{CFUs}\right)$, indicating that the high dose was near a $48 \mathrm{~h} \mathrm{LD}_{50}$ (lethal dose). Regardless, the surviving high-dose fish swam $\left(U_{\text {crit1 }}=\right.$ $\left.1.62 \pm 0.15 \mathrm{BL} \mathrm{s}^{-1}\right)$ and recovered $\left(U_{\text {crit2 }}=1.55 \pm 0.20 \mathrm{BL}\right.$ $\mathrm{s}^{-1}$ ) since their performance was not significantly different $(p=0.830, \beta=1.00)$ compared with salineinjected controls (Fig. 2).

\section{DISCUSSION}

The Listonella anguillarum injection protocol used herein successfully caused a subclinical vibriosis at injection levels similar to those of other studies (i.e. $10^{5} \mathrm{CFU}$; Ackerman et al. 1999, Ackerman \& Iwama 2001). In a natural setting, fish encounter this pathogen in the water column, and although it is uncertain whether this may result in more chronic infections, a stock can suffer complete mortality in as little as 5 d (Ackerman \& Iwama 2001). Our highdose protocol achieved $33.3 \%$ mortality in 2 d. Even at these near-lethal levels of $L$. anguillarum neither swimming performance nor its recovery were compromised. In fact, the overall performance of the injected fish remained comparable with control fish and with several other studies for similar-sized hatchery rainbow trout (1.6 to $1.7 \mathrm{BL} \mathrm{s}^{-1}$, this study; 0.53 to $0.94 \mathrm{BL}$ $\mathrm{s}^{-1}$, Taylor et al. 1996; $1.7 \mathrm{BL} \mathrm{s}^{-1}$, Duthie 1987; $2.0 \mathrm{BL} \mathrm{s}^{-1}$, Gallaugher et al. 1992). Thus, it appears that in the short term, the demands made on the immune system by L. anguillarum do not interact negatively with those of swimming.

We noted a small but significant increase in $U_{\text {crit }}$ with the low-dose injection. Jain \& Farrell (2003) proposed that fish may opt to swim to different $U_{\text {crit }}$ levels depending on either the water temperature or a resulting physiological condition. They found that warm-acclimated $\left(14.9^{\circ} \mathrm{C}\right)$ rainbow trout were able to achieve greater $U_{\text {crit1 }}$ values than cold-acclimated $\left(8.4^{\circ} \mathrm{C}\right)$ fish through increased use of anaerobic swimming. However, the increased $U_{\text {crit }}$ for the warmacclimated fish came at the cost of impaired reperformance (i.e. $U_{\text {crit2 }}$ was significantly lower than $U_{\text {crit1 }}$ ), a greater plasma ionic imbalance and a higher plasma cortisol level. In the present study, sublethal infection resulted in a $16.6 \%$ higher $U_{\text {crit1, a level that }}$ was maintained for $U_{\text {crit2 }}$. This response was unexpected and could have a behavioral or physiological basis, neither of which were explored here. For example, the elevated plasma cortisol levels previously shown to be associated with vibriosis (e.g. Ackerman et al. 1999 noted cortisol was elevated in rainbow trout at our low-dose $\left[10^{5} \mathrm{CFUs}\right] 24 \mathrm{~h}$ following injection, and Ackerman \& Iwama 2001 noted cortisol was elevated in rainbow trout $5 \mathrm{~d}$ following injection) may have stimulated swimming effort or altered swimming behavior. 


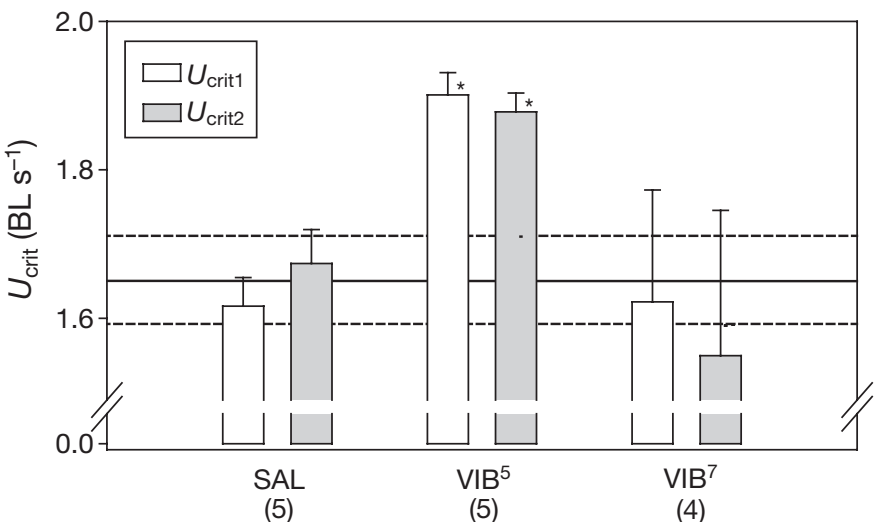

(5)

(4)
Fig. 2. Oncorhynchus mykiss. Ability of rainbow trout to perform $2 U_{\text {crit }}$ tests separated by $45 \mathrm{~min}, 48 \mathrm{~h}$ following saline (SAL) or a low- $\left(10^{5}\right)$ or high- $\left(10^{7}\right)$ dose Listonella anguillarum $\left(\mathrm{VIB}^{5}\right.$ and $\mathrm{VIB}^{7}$, respectively) injection. $U_{\text {crit }}$ values are standardized to body length (BL) and bars are mean + standard error of the mean (SEM); $\mathrm{n}$ is given below groups in parentheses; values significantly different from control are shown with asterisks (2-way repeated measures [RM] ANOVA, Holm-Sidak, $\mathrm{p}<0.05)$. $U_{\text {crit }} \pm 95$ CI for $(n=12)$ uninjected rainbow trout of the same stock are also shown with solid and dashed lines

Sublethal vibriosis had no effect on Hct or Lct compared with saline-injected fish. In fact, Hct was within the normal range for rainbow trout (Gallaugher et al. 1992). Vibriosis has been associated with anemia; for example, Harbell et al. (1979) noted Hct dropped from 37 to $15 \%$ as coho salmon Oncorhynchus kisutch became moribund $48 \mathrm{~h}$ following Listonella anguillarum exposure. Conversely, and in agreement with our findings, Ackerman \& Iwama (2001), who used an injection protocol similar to the one we used, found no change in Hct up to $7 \mathrm{~d}$ post-injection. Lct was more variable in saline-injected control fish, with normal Lct in 3 of the 5 (Wedemeyer et al. 1983), but a negligible Lct in 2 other fish. Since Lct was not detected after $L$. anguillarum injection, the injection may have caused a leucopoenia, but statistical power was weak. Ransom et al. (1984) reported earlier that Chinook salmon $O$. tshawytscha with vibriosis experienced an 80 to $95 \%$ decrease in circulating leucocytes. Since cortisol is known to be lymphocytolytic in salmonids (McLeay 1973), the elevated cortisol levels observed by others with $L$. anguillarum injection may be leucopenic. As McLeay (1973) pointed out, the destruction of lymphocytes may free up protein and enable gluconeogenesis that can in turn be used to fuel swimming.

This study is the first to demonstrate that Listonella anguillarum injection does not negatively affect $U_{\text {crit }}$ and its re-performance in rainbow trout, even at near lethal levels. The mechanism by which a sublethal vibriosis produced a modest increase in $U_{\text {crit }} 48 \mathrm{~h}$ postinjection will require further study.
Acknowledgements. We thank W. Challenger for statistical assistance, and the staff of the DFO/UBC Centre for Aquaculture and Environmental Research, West Vancouver, for onsite support. This work was funded by a Forest Renewal British Columbia grant to A.P.F.

\section{LITERATURE CITED}

Ackerman PA, Iwama GK (2001) Physiological and cellular responses of juvenile rainbow trout to vibriosis. J Aquat Anim Health 13:173-180

Ackerman PA, Forsyth RB, Iwama GK (1999) Acute vibriosis disease causes elevation of stress protein 70 in juvenile rainbow trout. Comp Biochem Physiol 124(Suppl):S43

Beamish FWH (1978) Swimming capacity of fish. In: Hoar WS, Randall DJ (eds) Fish physiology, Vol 7. Academic Press, New York, p 101-187

Black EC (1958) Hyperactivity as a lethal factor in fish. J Fish Res Board Can 15:573-586

Brauner CJ, Iwama GK, Randall DJ (1994) The effect of shortduration seawater exposure on the swimming performance of wild and hatchery-reared juvenile coho salmon (Oncorhynchus kisutch) during smolting. Can J Fish Aquat Sci 51:2188-2194

Brett JR (1964) The respiratory metabolism and swimming performance of young sockeye salmon. J Fish Res Board Can 21:1183-1226

Claireaux G, McKenzie DJ, Genge AG, Chatelier A, Aubin J, Farrell AP (2005) Linking swimming performance, cardiac pumping ability and cardiac anatomy in rainbow trout. J Exp Biol 208:1775-1784

DFO (Department of Fisheries and Oceans) (1984) Fish health protection regulations: manual of compliance. Fish Mar Serv Misc Spec Publ 31(Revised), Ottawa

Duthie GG (1987) Observations of poor swimming performance among hatchery reared rainbow trout, Salmo gairdneri. Environ Biol Fish 18:309-311

Egidius E (1987) Vibriosis: pathogenicity and pathology. A review. Aquaculture 67:15-28

Egidius EC, Anderson K (1979) Bath-immunization - a practical and non-stressing method of vaccinating sea farmed rainbow trout Salmo gairdneri Richardson against vibriosis. J Fish Dis 2:405-410

Farlinger S, Beamish FWH (1978) Changes in the blood chemistry and critical swimming speed of largemouth bass, Micropterus salmoides, with physical conditioning. Trans Am Fish Soc 107:523-527

Farrell AP, Gamperl AK, Birtwell IK (1998) Prolonged swimming, recovery and repeat swimming performance of mature sockeye salmon Oncorhynchus nerka exposed to moderate hypoxia and pentachlorophenol. J Exp Biol 201: 2183-2193

Farrell AP, Lee CG, Tierney K, Hodaly A, Clutterham S, Healey M, Hinch S, Lotto A (2003) Field-based measurements of oxygen uptake and swimming performance with adult $\mathrm{Pa}$ cific salmon (Oncorhynchus sp.) using a large mobile Bretttype respirometer swim tunnel. J Fish Biol 62:64-84

Gallaugher P, Axelsson M, Farrell AP (1992) Swimming performance and haematological variables in splenectomized rainbow trout, Oncorhynchus mykiss. J Exp Biol 171: 301-314

Harbell SC, Hodgins HO, Schiewe MH (1979) Studies on the pathogenesis of vibriosis in coho salmon Oncorhynchus kisutch (Walbaum). J Fish Dis 2:391-404

Jain KE, Farrell AP (2003) Influence of seasonal temperature on the repeat swimming performance of rainbow trout 
Oncorhynchus mykiss. J Exp Biol 206:3569-3579

Jain KE, Hamilton JC, Farrell AP (1997) Use of a ramp velocity test to measure critical swimming speed in rainbow trout (Oncorhynchus mykiss). Comp Biochem Physiol 117: 441-444

Jain KE, Birtwell IK, Farrell AP (1998) Repeat swimming performance of mature sockeye salmon following a brief recovery period: a sensitive measure of fish health and water quality. Can J Zool 76:1488-1496

Jones DT, Moffitt CM (2004) Swimming endurance of bull trout, lake trout, Arctic char, and rainbow trout following challenge with Renibacterium salmoninarum. J Aquat Anim Health 16:10-22

Lee CG, Devlin RH, Farrell AP (2003) Swimming performance, oxygen consumption and excess post-exercise oxygen consumption in adult transgenic and oceanranched coho salmon. J Fish Biol 62:753 doi:10.1046/j.1095-8649.2003.00057.x

McLeay DJ (1973) Effects of cortisol and dexamethasone on the pituitary-interrenal axis and abundance of white blood cell types in juvenile coho salmon, Oncorhynchus kisutch. Gen Comp Endocrin 21:441-450

McLeay DJ, Gordon MR (1977) Leucocrit: a simple hematological technique for measuring acute stress in salmonid fish, including stressful concentration of pulpmill effluent. J Fish Res Board Can 34:2164-2175

Nikl DL, Farrell AP (1993) Reduced swimming performance and gill structural changes in juvenile salmonids exposed to 2-(thiocyanomethylthio) benzothiazole. Aquat Toxicol $27: 245-264$

Editorial responsibility: Carl Schreck, Corvallis, Oregon, USA
Peake S, Barth C, McKinley RS (1997) Effect of recovery parameters on critical swimming speed of juvenile rainbow trout (Oncorhynchus mykiss). Can J Zool 75:1724-1727

Ransom DP, Lannan CN, Rohovec JS, Fryer JL (1984) Comparison of histopathology caused by Vibrio anguillarum and Vibrio ordalii in three species of Pacific salmon. J Fish Dis 7:107-115

Summerfelt RC, Smith LS (1990) Anesthesia, surgery, and related techniques. In: Schreck CB, Moyle PB (eds) Methods for fish biology. American Fisheries Society, Bethesda, MD, p 213-272

Swanson C, Baxa DV, Young PS, Cech JJ Jr, Hendrick RP (2002) Reduced swimming performance in delta smelt infected with Mycobacterium spp. J Fish Biol 61:1012-1020

Taylor SE, Egginton S, Taylor EW (1996) Seasonal temperature acclimation of rainbow trout: cardiovascular and morphometric influences on maximal sustainable exercise level. J Exp Biol 199:835-845

Tierney KB, Farrell AP (2004) The relationships between fish health, metabolic rate, swimming performance and recovery in return-run sockeye salmon, Oncorhynchus nerka (Walbaum). J Fish Dis 27:663-671

Wagner GN, McKinley RS, Bjørn PA, Finstad B (2003) Physiological impact of sea lice on swimming performance of Atlantic salmon. J Fish Biol 62:1000-1009

Wedemeyer GA, Gould RW, Yasutake WT (1983) Some potentials and limits of the leucocrit test as a fish health assessment method. J Fish Biol 23:711-718

Wood CM, Turner JD, Graham MS (1983) Why do fish die after severe exercise? J Fish Biol 22:189-201

Submitted: August 4, 2004; Accepted: September 3, 2005

Proofs received from author(s): October 24, 2005 